\title{
Levels, sources and health risks of carbonyls and BTEX in the ambient air of Beijing, China
}

\author{
Yujie Zhang ${ }^{1,2}$, Yujing $\mathrm{Mu}^{1, *}$, Junfeng $\mathrm{Liu}^{1}$, Abdelwahid Mellouki ${ }^{2}$ \\ 1. Research Center for Eco-Environmental Sciences, Chinese Academy of Sciences, Beijing 100085, China. E-mail: zhangyujie83@126.com \\ 2. Centre National de Recherche Scientifique - Institut de Combustion, Aérothermique, \\ Réactivité et Environnement (CNRS-ICARE), 45071 Orléans cedex 02, France
}

\begin{abstract}
The atmospheric concentrations of carbonyls and BTEX (benzene, toluene, ethylbenzene, $m, p$-xylene and $o$-xylene) were measured simultaneously at a same sampling site in Beijing from September 2008 to August 2010. The average concentrations of the total measured carbonyls during autumn, winter, spring, and summer were $37.7,31.3,39.7,50.5 \mu \mathrm{g} / \mathrm{m}^{3}$, respectively, and maximal values for their diurnal variations usually happened at noontime. In contrast to carbonyls, the average concentrations of the total measured BTEX during the four seasons were 27.2,31.9, 23.2, $19.1 \mu \mathrm{g} / \mathrm{m}^{3}$, respectively, and minimal values for their diurnal variations always occurred in the early afternoon. The average concentration for carbonyls increased about 24\% from September 2008-August 2009 to September 2009-August 2010, for BTEX, increased about 15\%. Integrated life time cancer risks for three carcinogens (benzene, formaldehyde and acetaldehyde) in Beijing exceeded the value of 1E-06, and the hazard quotient (HQ) of non-cancer risk of exposure to formaldehyde exceeded unity.
\end{abstract}

Key words: carbonyls; BTEX; sources; exposure and risk assessment; Beijing

DOI: $10.1016 /$ S1001-0742(11)60735-3

\section{Introduction}

Carbonyls and BTEX (benzene toluene ethylbenzene, $m, p$-xylene and $o$-xylene) in urban areas are one of the key problems for human living quality not only for their significant contribution in the formation of oxidants like ozone and peroxyacetyl nitrate (PAN) in the troposphere, but also for their adverse effects on human health (HaagenSmit and Fox, 1956; Atkinson et al., 1997, 1999, 2000; Hoque et al., 2008). The most frequently adverse impacts of carbonyls on human health are eye and lung irritations (Carlier et al., 1986; WHO, 2000), while for BTEX they are mainly respiratory irritation and central nervous system damage (Stupfel, 1976; Crump, 1994; Durmusohlu et al., 2010). Formaldehyde, acetaldehyde and benzene are even suspected to be carcinogenic (Stupfel, 1976; Crump, 1994; Carlier et al., 1986; Báez et al., 2003; Dutta et al., 2009). It has been estimated by the World Health Organization (WHO, 1999) that a life exposure of $1 \mu \mathrm{g} / \mathrm{m}^{3}$ of benzene leads to about 6 cases of leukaemia per 1,000,000 inhabitants. The large emission of fossil combustion in urban areas, such as automobile exhaust, has been recognized to be their dominant primary source (Anderson et al., 1996; Báez et al., 2003; Wang et al., 2002). In addition, photochemical reactions involving volatile organic compounds (VOCs) constitute another important source for atmospheric carbonyls.
Risk assessment is one of the fastest evolving tools to evaluate the impact of the hazards on human health and to determine the level of treatment required to solve a specific environmental problem (Asante-Duah, 1993; LaGrega et al., 1994). Pollutants are usually classified as carcinogens and non-carcinogens for estimating their human health risks. To better evaluate the health risks, long-term measurement of pollutants are needed, however, up to now the measurements of atmospheric carbonyls and BTEX in Beijing only focused on short periods, mainly during the periods of high ozone levels episodes typically from July to September (Song et al., 2007; Duan et al., 2008; Liu et al., 2009a, 2009b; Xu et al., 2010). With respect to long-term monitoring, only our group (Pang et al., 2006) conducted a one-year field campaign for atmospheric carbonyls from November 2004 to October 2005. Because of the incredibly fast change experienced by Beijing City, such as the fast increase rate of private cars (about $10 \%$ per year) and the series of air clean actions adopted by Beijing Municipal Government (Liu et al., 2009a), the atmospheric BTEX and carbonyls are expected to vary accordingly. In this study, carbonyls and BTEX were simultaneously investigated for two consecutive years (2008-2010) in Beijing to further reveal their pollution levels, to recognize their main sources and to estimate their cancer and non-cancer risks.

\footnotetext{
* Corresponding author. E-mail: yjmu@ rcees.ac.cn
} 


\section{Materials and methods}

\subsection{Sampling site}

Air samples were collected on a rooftop (20 m above the ground level) in the Research Center for EcoEnvironmental Sciences which lies in the north of Beijing City $\left(39.8^{\circ} \mathrm{N}, 116.5^{\circ} \mathrm{E}\right)$ between the 4th and 5th ring roads. The detail information about the sampling site was described in our previous studies (Pang and Mu, 2006; Liu et al., 2009a).

\subsection{Sampling and analysis}

Carbonyls and BTEX were simultaneously sampled at least 4 days per month from September 2008 to August 2010, with carbonyls' samples collected at $2 \mathrm{hr}$ interval and BTEX at $1 \mathrm{hr}$ interval. Nearly all kinds of weather were selected each month to collected samples, excepting raining day: at least one clear day, one cloudy day, one haze day with average wind speed lower than $3 \mathrm{~m} / \mathrm{sec}$, and one windy day with hourly average windy speed higher than 8 $\mathrm{m} / \mathrm{sec}$.

The sampling process and analysis procedure of atmospheric carbonyls were mainly based on the US EPA TO-11A method (US EPA, 1999), and the details have been described in our previous publications (Pang and $\mathrm{Mu}$, 2006, 2007). Briefly, ambient air was drawn through a 2,4dinitrophenylhydrazine (DNPH)-coated silica gel cartridge (Waters, USA) by a mini-pump (NMP 830 KNDC, Germany) at a flow rate of $800 \mathrm{~mL} / \mathrm{min}$ for $2 \mathrm{hr}$, and the corresponding DNPH hydrazones of carbonyls were separated by a Thermo ODS Hypersil reverse phase column (5 $\mu \mathrm{m}, 250 \mathrm{~mm} \times 4.6 \mathrm{~mm}$ ) and automatically analyzed by an photodiode array UV detector (at $360 \mathrm{~nm}$ ) in an Alliance 2695 HPLC system (Waters, USA). The detected limit ( $/ N$ $=3$ ) by this method was in the range of $80-200 \mathrm{ng} / \mathrm{m}^{3}$ for various carbonyls of $96 \mathrm{~L}$ sampling volume.

As for BTEX, they were sampled by drawing air through an absorption tube (15 cm long, $4 \mathrm{~mm}$ ID) filled with Tenax-TA (80-100 mesh, $100 \mathrm{mg}$ ) at a flow rate of 350 $\mathrm{mL} / \mathrm{min}$ for $1 \mathrm{hr}$, and analyzed by a gas chromatography equipped with a Photo Ionization Detector (GC-PID, GC4400, East \& West Analytical Instruments, Inc., China) after thermal desorption. The method detection limit (with a signal-to-noise ratio of 2) for the benzene, toluene, ethylbenzene, $m, p$-xylene and $o$-xylene were $0.01,0.02$, $0.06,0.07$ and $0.07 \mu \mathrm{g} / \mathrm{m}^{3}$, respectively. One blank sample was analyzed for each day, and found that the concentrations of BTEX in the blank tube were less than $3 \%$ of those in the ambient air samples. Distinct breakthrough for benzene was found when the absorption tube was kept under ambient air temperature, but greatly improved when the tube was kept in a bath of ice-salt bag. Therefore, all samples were collected under the bath of ice-salt bag, and the collection efficiencies for benzene, toluene, ethylbenzene, $m, p$-xylene and $o$-xylene were $(81.5 \pm 5.6) \%$, $(93.6 \pm 2.2) \%,(95.8 \pm 0.8) \%,(96.5 \pm 2.4) \%$ and $(91.5$ $\pm 4.6) \%$ (the result of 10 reduplicate experiments with two absorption tubes in series), respectively. The recovery ratios for benzene, toluene, ethylbenzene, $m, p$-xylene and $o$-xylene were $(95.7 \pm 3.1) \%,(99.2 \pm 2.6) \%,(98.6 \pm$ $2.4) \%,(98.1 \pm 2.4) \%$ and $(96.2 \pm 2.2) \%$ (the result of 22 reduplicate experiments), respectively. The details about preparation of the absorption tube, sampling and analyzing procedures have been described in our previous publication (Liu et al., 2009a).

Meteorological conditions (temperature, wind speed, atmospheric pressure and precipitation) during the investigated years were recorded by an automatic meteorological station (the Beijing Urban Ecosystem Research Station, Research Center for Eco-Environmental Sciences).

\section{Results and discussion}

\subsection{Average diurnal variation of carbonyls in each sea- son during the two consecutive years}

Eight carbonyls were identified in the ambient air, namely formaldehyde, acetaldehyde, acetone, propionaldehyde, butyraldehyde, benzaldehyde, valeraldehyde and hexaldehyde among which formaldehyde, acetaldehyde and acetone were by far the principal carbonyls and could be detected in every sample. The average diurnal variation of the three main carbonyls and the total eight carbonyl compounds in each season during the two consecutive years are presented together in Fig. 1. The ranges and arithmetic mean concentrations of the three principal aldehydes measured in this study and our previous study (Pang and $\mathrm{Mu}, 2006)$ at the same sampling site in each season are shown in Table 1. It is evident that the measured carbonyls

Table 1 Average concentrations $\left(\mu \mathrm{g} / \mathrm{m}^{3}\right)$ of the three main carbonyls in each season during different investigated years

\begin{tabular}{|c|c|c|c|c|c|c|c|c|c|}
\hline \multirow[t]{2}{*}{ Season } & \multirow[t]{2}{*}{ Year } & \multirow{2}{*}{$\begin{array}{l}\text { Number of } \\
\text { samples }\end{array}$} & \multicolumn{2}{|c|}{ Formaldehyde } & \multicolumn{2}{|c|}{ Acetaldehyde } & \multicolumn{2}{|c|}{ Acetone } & \multirow[t]{2}{*}{ Reference } \\
\hline & & & Mean \pm SD & Range & Mean \pm SD & Range & Mean \pm SD & Range & \\
\hline \multirow[t]{3}{*}{ Autumn } & 2008 & 157 & $5.9 \pm 3.2$ & $0.4-17.7$ & $6.6 \pm 4.2$ & $0.5-24.5$ & $13.1 \pm 7.1$ & $1.8-38.9$ & This work \\
\hline & 2009 & 88 & $8.3 \pm 5.8$ & $0.5-28.7$ & $9.8 \pm 6.8$ & $1.5-34.3$ & $22.1 \pm 13.1$ & $4.6-50.3$ & This work \\
\hline & 2005 & 72 & $15.8 \pm 9.7$ & $3.7-45.6$ & $16.2 \pm 7.2$ & $3.7-45.6$ & $15.8 \pm 9.7$ & $2.8-30.4$ & Pang and $\mathrm{Mu}, 2006$ \\
\hline \multirow[t]{3}{*}{ Winter } & 2008 & 116 & $4.8 \pm 4.5$ & $0.1-20.6$ & $6.0 \pm 5.7$ & $0.4-22.7$ & $11.6 \pm 6.8$ & $0.4-38.9$ & This work \\
\hline & 2009 & 90 & $4.3 \pm 3.3$ & $0.4-13.2$ & $5.3 \pm 3.6$ & $0.9-14.7$ & $16.0 \pm 6.9$ & $4.5-40.7$ & This work \\
\hline & 2004 & 86 & $4.2 \pm 2.8$ & $1.1-12.1$ & $7.6 \pm 5.3$ & $1.4-30.1$ & $7.8 \pm 4.6$ & $1.8-25.3$ & Pang and $\mathrm{Mu}, 2006$ \\
\hline \multirow[t]{3}{*}{ Spring } & 2009 & 124 & $5.3 \pm 3.9$ & $0.1-20.6$ & $6.8 \pm 4.4$ & $0.9-24.1$ & $16.4 \pm 8.7$ & $3.8-49.9$ & This work \\
\hline & 2010 & 84 & $6.6 \pm 3.7$ & $0.7-16.2$ & $6.9 \pm 3.5$ & $0.4-15.3$ & $28.9 \pm 8.7$ & $8.8-44.0$ & This work \\
\hline & 2005 & 120 & $14.5 \pm 8.7$ & $1.9-45.8$ & $12.5 \pm 6.6$ & $1.1-32.9$ & $16.2 \pm 7.2$ & $1.3-38.7$ & Pang and $\mathrm{Mu}, 2006$ \\
\hline \multirow[t]{3}{*}{ Summer } & 2009 & 116 & $8.8 \pm 4.7$ & $0.9-23.9$ & $9.5 \pm 5.1$ & $1.0-26.0$ & $19.3 \pm 7.5$ & $7.3-40.2$ & This work \\
\hline & 2010 & 90 & $10.2 \pm 4.2$ & $0.2-18.6$ & $9.7 \pm 3.9$ & $0.5-18.1$ & $28.7 \pm 10.8$ & $10.6-82.5$ & This work \\
\hline & 2005 & 110 & $19.5 \pm 8.9$ & $2.6-52.9$ & $14.1 \pm 7.4$ & $1.8-35.7$ & $20.7 \pm 9.9$ & $10.6-53.2$ & Pang and $\mathrm{Mu}, 2006$ \\
\hline
\end{tabular}



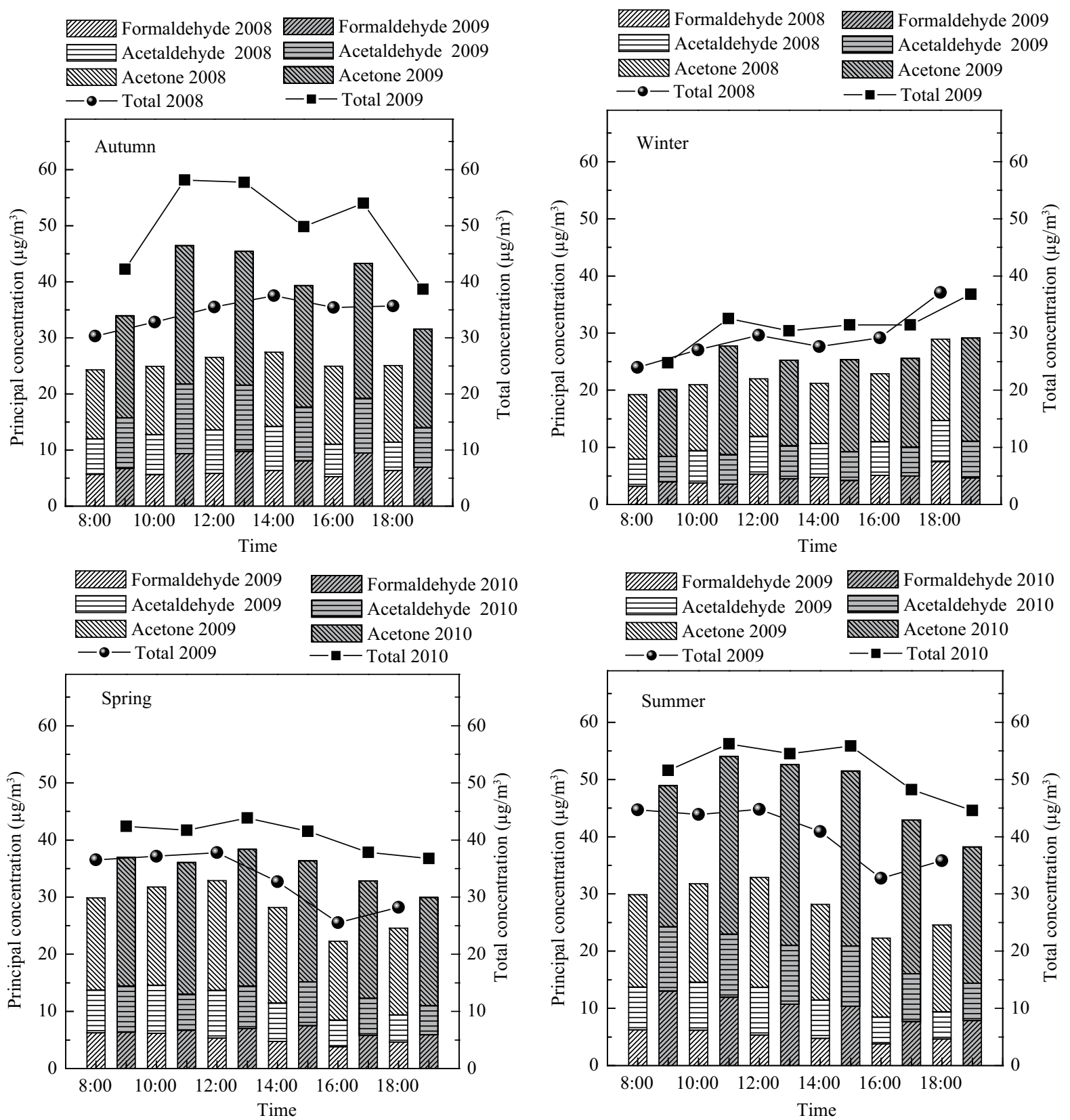

Fig. 1 Average diurnal variations of the three main and the total eight carbonyls in each season during the two consecutive years.

exhibited distinct seasonal and diurnal variations. The average concentrations of the total measured carbonyls during two consecutive years in autumn, winter, spring, and summer were $37.7,31.3,39.7,50.5 \mu \mathrm{g} / \mathrm{m}^{3}$, respectively. Maximal values for their diurnal variations usually happened around noontime in seasons other than winter. Both the seasonal and diurnal variations indicated that local photooxidation of VOCs made a great contribution to the observed carbonyls, e.g., the maximum contributions of local photooxidation to formaldehyde and acetaldehyde were calculated to be $70 \%-80 \%$ and $60 \%-70 \%$, respectively during summer in Beijing according to our another study. Figure 1 also reveals that both the 2-hr average concentrations of the sum of the three principal carbonyls and the total eight carbonyls in each season during the second investigated year (Sep 2009-Aug 2010) were much higher than those of the first year (Sep 2008-Aug 2009).
The increment of the average total carbonyls concentration from the first year to the second year was probably ascribed to the increment of emissions of the primary carbonyls and their precursors, e.g., the number of cars increases by $10 \%$ every year in Beijing since 2006 (Liu et al., 2009).

As shown in Table 1, the mean concentrations of formaldehyde and acetaldehyde during each season in this study were significantly lower than our previous investigation (Pang and Mu, 2006), whereas the variation trend of mean acetone concentrations during the investigated years was not as clear as those of formaldehyde and acetaldehyde, even contrary to their trend during winter. The exhaust of vehicles in the urban areas is usually considered as the dominant sources of various pollutants (Anderson et al., 1996; Báze et al., 2003; Dutta et al., 2009), especially for the megacity of Beijing that almost all factories with pollutants emission have been moved outside for purpose 
of improving the air quality. The decrease of atmospheric formaldehyde and acetaldehyde during the two investigated years in comparison with the previous year seemed to be contrary to the sharp increment of the number of cars, e.g., the number of cars in 2009 and 2010 increased nearly twice of those in our previous investigation year of 2004 and 2005 (Liu, 2009a). Thus it was suspected that the more strict emission standard enacted for cars in Beijing, such as the vehicles with exhaust emissions failed to meet the European No.1 standard were all-day forbidden on the roads since 1 July, 2008 (BOCOG, 2005; Hao and Wang., 2005), was the main reason for the decrease of atmospheric formaldehyde and acetaldehyde. As for acetone, irregular
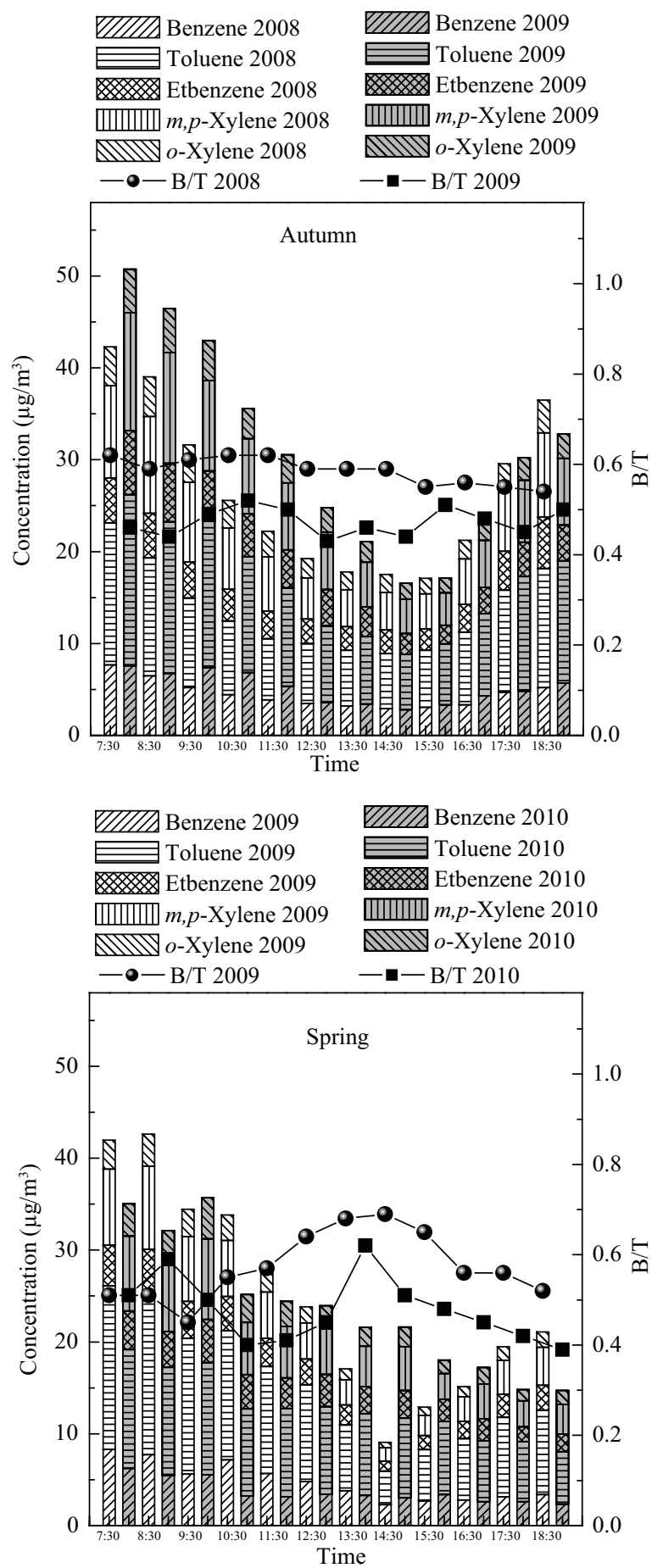

emissions, such as evaporation of solvents and paints etc. might be its dominant sources.

\subsection{Average diurnal variation of BTEX in each season during the two consecutive years}

The seasonal and diurnal variations of BTEX during the two consecutive years are shown in Fig. 2, and the ranges and arithmetic mean concentrations of BTEX are listed in Table 2. In contrast to the carbonyls, the order of the seasonal variation of the mean BTEX concentration were: winter $\left(31.9 \mu \mathrm{g} / \mathrm{m}^{3}\right)>$ autumn $\left(27.2 \mu \mathrm{g} / \mathrm{m}^{3}\right)>$ spring $\left(23.2 \mu \mathrm{g} / \mathrm{m}^{3}\right)>\operatorname{summer}\left(19.1 \mu \mathrm{g} / \mathrm{m}^{3}\right)$, the minimal values for their diurnal variations usually happened in the

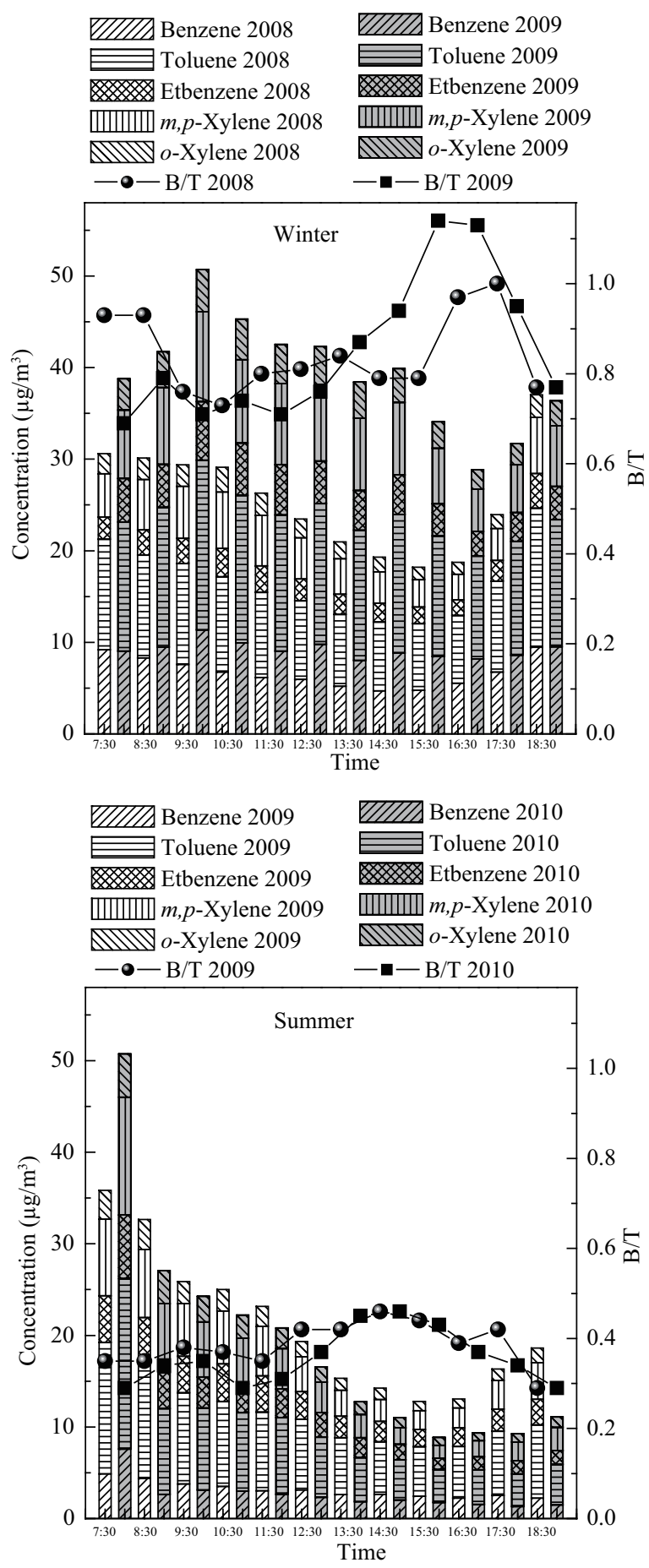

Fig. 2 Average diurnal variation of BTEX and the ratio of benzene/toluene (B/T) in each season during the two consecutive years. 
Table 2 Average concentrations $\left(\mu \mathrm{g} / \mathrm{m}^{3}\right)$ of BTEX in each season during different investigated years

\begin{tabular}{|c|c|c|c|c|c|c|c|c|c|c|c|c|}
\hline \multirow[b]{2}{*}{ Season } & \multirow[t]{2}{*}{ Year } & \multirow{2}{*}{$\begin{array}{l}\text { Number of } \\
\text { Samples }\end{array}$} & \multicolumn{2}{|c|}{ Benzene } & \multicolumn{2}{|c|}{ Toluene } & \multicolumn{2}{|c|}{ Etbenzene } & \multicolumn{2}{|c|}{$m, p$-Xylene } & \multicolumn{2}{|c|}{$o$-Xylene } \\
\hline & & & Mean \pm SD & Range & Mean \pm SD & Range & Mean \pm SD & Range & Mean \pm SD & Range & Mean \pm SD & Range \\
\hline \multirow[t]{2}{*}{ Autumn } & 2008 & 590 & $4.6 \pm 4.4$ & $0.2-35.4$ & $8.5 \pm 8.3$ & $0.4-50.2$ & $3.4 \pm 3.2$ & $0.1-23.4$ & $5.7 \pm 5.0$ & $0.1-27.0$ & $2.8 \pm 2.5$ & $0.1-19.2$ \\
\hline & 2009 & 162 & $5.1 \pm 4.4$ & $0.2-21.2$ & $11.2 \pm 9.6$ & $0.7-44.3$ & $4.1 \pm 3.3$ & $0.2-13.2$ & $7.2 \pm 5.8$ & $0.4-25.5$ & $2.8 \pm 2.2$ & $0.3-8.9$ \\
\hline \multirow[t]{2}{*}{ Winter } & 2008 & 190 & $6.9 \pm 6.7$ & $0.9-24.1$ & $10.4 \pm 10.6$ & $0.8-41.0$ & $2.5 \pm 2.5$ & $0.2-11.9$ & $4.9 \pm 4.4$ & $0.4-21.9$ & $2.2 \pm 2.0$ & $0.2-9.9$ \\
\hline & 2009 & 140 & $9.2 \pm 7.6$ & $0.8-31.2$ & $14.5 \pm 13.2$ & $1.2-58.7$ & $4.4 \pm 4.5$ & $0.3-18.2$ & $7.5 \pm 7.1$ & $0.6-34.1$ & $3.5 \pm 3.2$ & $0.3-14.8$ \\
\hline \multirow{2}{*}{ Spring } & 2009 & 236 & $4.8 \pm 4.6$ & $0.2-32.3$ & $9.4 \pm 8.6$ & $0.5-42.3$ & $2.7 \pm 2.6$ & $0.1-15.1$ & $4.3 \pm 4.2$ & $0.3-20.0$ & $1.8 \pm 1.7$ & $0.1-7.8$ \\
\hline & 2010 & 144 & $3.7 \pm 3.0$ & $0.2-15.6$ & $9.2 \pm 7.1$ & $0.6-27.3$ & $3.2 \pm 2.6$ & $0.2-11.3$ & $5.3 \pm 4.4$ & $0.3-17.7$ & $2.6 \pm 2.1$ & $0.1-11.1$ \\
\hline \multirow[t]{2}{*}{ Summer } & 2009 & 218 & $3.2 \pm 2.3$ & $0.3-11.9$ & $8.6 \pm 5.5$ & $0.8-26.7$ & $3.3 \pm 2.1$ & $0.4-10.2$ & $4.6 \pm 3.4$ & $0.5-15.9$ & $1.9 \pm 1.3$ & $0.3-7.4$ \\
\hline & 2010 & 178 & $2.1 \pm 1.5$ & $0.2-8.0$ & $5.9 \pm 3.6$ & $1.2-17.9$ & $2.3 \pm 1.3$ & $0.5-10.0$ & $3.4 \pm 2.3$ & $0.4-9.9$ & $1.7 \pm 1.1$ & $0.4-9.9$ \\
\hline
\end{tabular}

early afternoon, and only the concentrations in winter and autumn during the second investigated year (Sep 2009Aug 2010) were much higher (ca. 38\%) than those of the first year (Sep 2008-Aug 2009). The evident difference between the carbonyls and BTEX was mainly ascribed to their different sources, that is, only primary sources contribute to atmospheric BTEX, while, as mentioned above, the photochemical conversions of VOCs are the dominant sources for atmospheric carbonyls, especially for the seasons other than winter. Besides sources' strength, the seasonal and diurnal variations of atmospheric BTEX in urban areas also strongly depend on meteorological conditions and photochemical activity. The frequent inverse temperature layer during winter season and stable meteorological condition in autumn that prevailed in Beijing, hinder the dilution of the pollutants, and thus led to higher concentrations of BTEX in the atmosphere. The frequent windy days in spring and strong photochemical activity in summer accounted for the low concentration of the observed BTEX. The relatively high concentration during rush hours in the morning and late afternoon implied that automobile exhaust was an important source for atmospheric BTEX in Beijing. The ratio of benzene to toluene $(\mathrm{B} / \mathrm{T})$ has been widely used as an indicator for distinguishing their various sources from vehicle emission. Investigating 27 roadside samples from 25 different cities, Barletta et al. (2005) concluded that an average B/T value of 0.6 (wt./wt.) $(\sigma=0.2)$ could be used to characterize vehicle emissions. Liu et al. (2005) also reported the B/T ratio was 0.61 from roadside in Beijing. The $\mathrm{B} / \mathrm{T}$ values obtained in this study in autumn and spring were well within the reported range of vehicle emission, however, the $B / T$ values in winter and summer were beyond the range. The extremely high $\mathrm{B} / \mathrm{T}$ values in winter indicated the sources other than vehicle emission made great contribution to atmospheric benzene and toluene, e.g. central heating during winter in Beijing. The $\mathrm{B} / \mathrm{T}$ ratio higher than unity has been reported for cities mainly dominated by coal burning (Barletta et al., 2005, 2008). Although most of central heating stoves that used coal as energy in Beijing have been replaced by the relatively clean energies of oil or natural gas since 1999, there are still a number of domestic stoves using coal for heating, and the emission from the domestic stoves might be responsible for the observed high $\mathrm{B} / \mathrm{T}$ ratios in winter. The extremely low $\mathrm{B} / \mathrm{T}$ in summers during the two investigated years was inconsistent with our previous study (Liu et al., 2010) which revealed that the $\mathrm{B} / \mathrm{T}$ ratios during 2008 summer were around 0.6. Because strict control measures for the "green Olympic Games" in 2008 were enacted during the special summer, vehicle emission might become the dominant source for atmospheric benzene and toluene. Thus, we suspected that the sources other than vehicle emission (such as the emissions from painting and gas stations etc. due to the relatively high ambient temperature) during the two investigated summer seasons might make great contribution to atmospheric benzene and toluene

\subsection{Exposure and risk assessment}

As mentioned in the Introduction section, atmospheric carbonyls and BTEX have adverse impact on human health, and formaldehyde, acetaldehyde and benzene are suspected to be carcinogenic (Báez et al., 2003; Dutta et al., 2009). In order to evaluate the threat to the Beijing inhabitants health caused by carbonyls and BTEX, the noncancer hazard and integrated lifetime cancer risk (ILTCR) due to the exposure to formaldehyde, acetaldehyde and BTEX were estimated based on the data measured in this study.

The daily exposure $(E)$ of an individual by intake process (only inhalation was considered) was calculated from Eq. (1):

$E=C \times I_{\mathrm{ra}} \times E_{\mathrm{da}} / B_{\mathrm{wa}}$

\begin{tabular}{lll}
\hline Variable & Description & Value \\
\hline$E(\mathrm{mg} /(\mathrm{kg} \cdot$ day $))$ & Daily exposure & \\
$C\left(\mathrm{mg} / \mathrm{m}^{3}\right)$ & Concentration of the pollutant & \\
$I_{\mathrm{ra}}\left(\mathrm{m}^{3} / \mathrm{hr}\right)$ & Inhalation rate*, adult & $0.83^{*}$ \\
$E_{\mathrm{da}}(\mathrm{hr} / \mathrm{day})$ & Exposure duration, adult & 24 \\
$B_{\mathrm{wa}}(\mathrm{kg})$ & Body weigh, adult & 65 \\
\hline The value of inhalation rate $($ adult $)$ is taken from US EPA (1997)
\end{tabular}

The ILTCR was calculated from Eq. (2):

$\mathrm{ILTCR}=E \times \mathrm{SF}$

where, SF (mg/(kg.day)) is a slope factor of inhalation unit risk for toxics when the exposurecarcinogenic effect is considered as linear, taking from EPA (http://www.epa.gov/iris).

Non-cancer risk was expressed as hazard quotient (HQ), which is defined as the ratio of yearly average daily received concentration (LEC) and the reference concentration (RfC).

$\mathrm{HQ}=\mathrm{LEC} / \mathrm{RfC}$ 
If $\mathrm{HQ}>1$, it indicates long term exposure may result in adverse health effects. The RfC for each pollutant was taken from EPA (http://rais.ornl.gov) and California Office of Environmental Health Hazard Assessment (http://www.arb.ca.gov/toxics/healthval/acute.pdf).

Based on the above equations, the average daily exposure, individual HQ and ILTCR were estimated and listed in Table 3. Among the carcinogens, the ILTCR integrated lifetime cancer risk of formaldehyde was found to be the highest, followed by benzene and then acetaldehyde, and all of them exceeded the value of 1E-06, indicating significant cancer risk (Dutta et al., 2009). The individual HQs of formaldehyde exceeded unity, indicating chronic health effect. It should be mentioned that the above estimation only considered the outdoor pollution, whereas, due to the delicate decoration, the indoor carbonyls (especially for formaldehyde) and BTEX are more serious than outdoors (Wang et al., 2007) and urban residents spent their more time inside, and hence the estimations can only represent the lower limits. In addition, it is known that the carbonyls and BTEX were the dominant precursors for atmospheric photo-oxidants which will further induce their indirect health impact on residents as well as ecosystems. Therefore, further control measures are urgently needed for mitigating the emissions of these poisonous compounds in Beijing. Because vehicle emission is an important source for BTEX and carbonyls (including the indirect source), and the number of cars in Beijing has exceeded 4.9 million, to effectively mitigate vehicle emission, besides more strict emission standard enacting, the current traffic status of prevailing traffic congestion with high pollutant's emission is urgently needed to be improved.

Table 3 Estimate of individual pollutant exposure, associated non-cancer hazard and cancer risk during the two investigated years

\begin{tabular}{lllll}
\hline Pollutant & $\begin{array}{l}\text { Yearly average } \\
\text { concentration } \\
\left(\mathrm{mg} / \mathrm{m}^{3}\right)\end{array}$ & $\begin{array}{l}\text { Daily average } \\
\text { exposure } \\
(\mathrm{mg} /(\mathrm{kg} \cdot \text { day }))\end{array}$ & HQ & ITLCR \\
\hline Formaldehyde & $6.61 \mathrm{E}-03$ & $2.03 \mathrm{E}-03$ & $3.30 \mathrm{E}+00$ & $9.11 \mathrm{E}-05$ \\
Acetaldehyde & $7.50 \mathrm{E}-03$ & $2.30 \mathrm{E}-03$ & $8.34 \mathrm{E}-01$ & $1.84 \mathrm{E}-05$ \\
Benzene & $4.72 \mathrm{E}-03$ & $1.45 \mathrm{E}-03$ & $1.57 \mathrm{E}-01$ & $4.19 \mathrm{E}-05$ \\
Toluene & $9.58 \mathrm{E}-03$ & $2.93 \mathrm{E}-03$ & $2.39 \mathrm{E}-02$ & \\
Etbenzene & $3.29 \mathrm{E}-03$ & $1.01 \mathrm{E}-03$ & $3.29 \mathrm{E}-03$ & \\
$m, p$-Xylene & $5.64 \mathrm{E}-03$ & $1.73 \mathrm{E}-03$ & $8.06 \mathrm{E}-03$ & \\
$o-X y l e n e$ & $2.74 \mathrm{E}-03$ & $7.58 \mathrm{E}-04$ & $3.53 \mathrm{E}-03$ & \\
\hline
\end{tabular}

HQ: hazard quotient; ILTCR: integrated lifetime cancer risk.

\section{Conclusions}

Distinct diurnal and seasonal variations of atmospheric BTEX and carbonyls at a sampling site in Beijing were observed, implying vehicular exhaust was an important sources for BTEX and photochemical conversion of hydrocarbons (especially for the seasons other than winter) was dominant source for carbonyls. Additionally, domestic stoves used coal as energy made significant contribution to BTEX during winter, and the evaporation of painting and solvents etc. also made evident contribution to BTEX in summer. The obvious yearly increase of the carbonyls and BTEX (especially during autumn and winter) indicated their sources' strength was still increasing, which might be ascribed to the increase of the number of cars. The assessments of health risk based on the data investigated in the two consecutive years revealed that the exposures to the atmospheric benzene, formaldehyde and acetaldehyde exceeded the value (1E-06) of the integrated lifetime cancer risk, and the HQ of non-cancer risk of exposure to formaldehyde exceeded unity, indicating significant health risk. Therefore, effective control measures are urgently needed to improve the current pollution status of Beijing.

\section{Acknowledgments}

This work was supported by the National Natural Science Foundation of China (No. 41075094, 40830101, 21177140, 20977097), the National Basic Research and the Development Program (973) of China (No. 2010CB732304), the Special Fund for Environmental Research in the Public Interest (No. 201009001), the National Water Special Project (No. 2009ZX07210-009).

\section{References}

Anderson L G, Lanning J A, Barrell R, Miyaishima J, Jones RH, Wolfe P, 1996. Sources and sinks of formaldehyde and acetaldehyde: an analysis of denver's ambient concentration data. Atmospheric Environment, 30(12): 2113-2123.

Asante-Duah D K, 1993. Hazardous Waste Risk Assessment. Lewis Publishers, FL, USA.

Atkinson R, Baulch D L, Cox R A, Hampson R F J, Kerr J A, Rossi M J et al., 1999. Evaluated kinetic and photochemical data for atmospheric chemistry, Organic species: Supplement VII. Journal of Physical and chemical reference Data, 28(2): 391-393.

Atkinson R, 1997. Gas-phase tropospheric chemistry of volatile organic compounds 1. Alkanes and alkenes. Journal of Physical and Chemical Reference Data, 26(2): 215-290.

Atkinson R, 2000. Atmospheric chemistry of VOCs and NOx. Atmospheric Environment, 34(12-14): 2063-2101.

Báez A P, Padillah H, García R, Torres Mdel C, Rosas I, Belmont $\mathrm{R}$, 2003. Carbonyl levels in indoor and outdoor air in Mexico City and Xalapa, Mexico. Science of the Total Environment, 302(1-3): 211-226.

Barletta B, Meinardi S, Rowland F S, Chan C Y, Wang X M, Zou S C et al., 2005. Volatile organic compounds in 43 Chinese cities. Atmospheric Environment, 39(32): 5979-5990.

Barletta B, Meinardi S, Simpson I J, Zou S C, Rowland F S, Blake D R, 2008. Ambient mixing ratios of nonmethane hydrocarbons (NMHCs) in two major urban centers of the Pearl River Delta (PRD) region: Guangzhou and Dongguan. Atmospheric Environment, 42(18): 4393-4408.

Beijing Organizing Committee for the Games of the XXIX Olympic Games (BOCOG), 2005. Green Olympics in Beijing, 2005. http://en.beijing2008. cn/bocog/environment/guidelines/n214068405.shtml.

Carlier P, Hannachi H, Mouvier G, 1986. The chemistry of carbonyl compounds in the atmosphere - A review. Atmospheric Environment, 20(11): 2079-2099.

Crump K S, 1994. Risk of benzene-induced leukemia: A sensitivity analysis of the pliofilm cohort with additional follow-up and new exposure estimates. Journal of Toxicology and 
Environmental Health, 42(2): 219-242.

Duan J C, Tan J H, Yang L, Wu S, Hao J M, 2008. Concentration, sources and ozone formation potential of volatile organic compounds (VOCs) during ozone episode in Beijing. Atmospheric Research, 88(1): 25-35.

Durmusoglu E, Taspinar F, Karademir A, 2010. Health risk assessment of BTEX emissions in the landfill environment. Journal of Hazardous Materials, 176(1-3): 870-877.

Dutta C, Som D, Chatterjee A, Mukherjee A K, Jana T K, Sen S, 2009. Mixing ratios of carbonyls and BTEX in ambient air of Kolkata, India and their associated health risk. Environmental Monitoring and Assessment, 148(1-4): 97-107.

Haagen-Smit A J, Fox M M, 1956. Ozone formation in photochemical oxidation of organic substances. Industial $\mathcal{E}$ Engineering Chemistry, 48(9): 1484-1487.

Hao J M, Wang L T, 2005. Improving urban air quality in China: Beijing case study. Journal of the Air $\mathcal{E}$ Waste Management Association, 55(9): 1298-1305.

Hoque R R, Khillare P S, Agarwal T, Shridhar V, Balachandran S, 2008. Spatial and temporal variation of BTEX in the urban atmosphere of Delhi, India. Science of the Total Environment, 392(1): 30-40.

LaGrega M D, Buckingham P L, Evans J C, 1994. Hazardous Waste Management. McGraw Hill, New York.

Liu J F, Mu Y J, Zhang Y J, Zhang Z M, Wang X K, Liu Y J et al., 2009a. Atmospheric levels of BTEX compounds during the 2008 Olympic Games in the urban area of Beijing. Science of the Total Environment, 408(1): 109-116.

Liu Y, Shao M, Zhang J, Fu L L, Lu S H, 2005. Distributions and source apportionment of ambient volatile organic compounds in Beijing City, China. Journal of Environmental Science Health Part A Toxic/Hazardous Substances and Environmantal Engineering, 40(10): 1843-1860.

Liu Y, Shao M, Kuster W C, Goldan P D, Li X H, Lu S H et al., 2009b. Source identification of reactive hydrocarbons and oxygenated VOCs in the summertime in Beijing. Environ- mental Science $\mathcal{E}$ Technology, 43(1): 75-81.

Pang X B, Mu Y J, 2006. Seasonal and diurnal variations of carbonyl compounds in Beijing ambient air. Atmospheric Environment, 40(33): 6313-6320.

Pang X B, Mu Y J, 2007. Characteristics of carbonyl compounds in public vehicles of Beijing City: concentrations, sources, and personal exposures. Atmospheric Environment, 41(9): 1819-1824.

Song Y, Shao M, Liu Y, Lu S H, Kuster W, Goldan P et al., 2007. Source apportionment of ambient volatile organic compounds in Beijing. Environmental Science E Technology, 41(12): 4348-4353.

Stupfel M, 1976. Recent advances in investigations of toxicity of automotive exhaust. Environmental Health Perspectives, 17: 253-285.

US EPA, 1997. Air risk assessment workplan.

US EPA, 1999. Compendium of Methods for the Determination of Toxic Organic Compounds in Ambient Air (2nd ed.).

Wang B, Lee S C, Ho K F, 2007. Characteristics of carbonyls: Concentrations and source strengths for indoor and outdoor residential microenvironments in China. Atmospheric Environment, 41(13): 2851-2861.

Wang X M, Sheng G Y, Fu J M, Chan C Y, Lee S C, Chan L Y et al., 2002. Urban roadside aromatic hydrocarbons in three cities of the Pearl River Delta, People's Republic of China. Atmospheric Environment, 36(33): 5141-5148.

World Health Organization, 1999. Air Quality Guidelines for Europe. WHO Regional Publication, European Series. World Health Organization, Regional Office for Europe, Copenhagen.

WHO, 2000. Air quality guidelines for Europe. WHO Regional Publications, European Series, Copenhagen, Denmark, 91: 87-91.

Xu Z, Liu J F, Zhang Y J, Liang P, Mu Y J, 2010. Ambient levels of atmospheric carbonyls in Beijing during the 2008 Olympic Games. Journal of Environmental Sciences, 22(9): 1348-1356. 